\title{
Tingkat Pengetahuan, Sikap, dan Perilaku Remaja tentang Kesehatan Reproduksi di SMK Negeri 8 Medan
}

\author{
Iqbal Pahlevi Adeputra Nasution ${ }^{1}$, Binsyah Sari Indah Gajah Manik ${ }^{1}$ \\ ${ }^{1}$ Departemen Bedah, Fakultas Kedokteran, Universitas Sumatera Utara, Medan
}

\begin{abstract}
ABSTRAK
Latar Belakang: Kesehatan reproduksi merupakan salah satu hal yang sangat penting bagi kehidupan manusia yaitu mencakup keadaan sejahtera baik fisik, mental, sosial yang utuh dalam segala hal yang berkaitan dengan fungsi, peran dari sistem reproduksi. Pendidikan kesehatan reproduksi sebaiknya diberikan sejak remaja, karena remaja merupakan fase menuju reproduksi yang lebih matang. Permasalahan remaja yang berkaitan dengan kesehatan reproduksi, sering kali berakar dari kurangnya informasi, pemahaman dan kesadaran untuk mencapai keadaan sehat secara reproduksi. Tujuan: Penelitian ini bertujuan untuk mengetahui tingkat pengetahuan, sikap dan perilaku remaja tentang kesehatan reproduksi di SMK Negeri 8 Medan. Metode: Penelitian ini adalah studi deskriptif dengan desain cross sectional. Data penelitian adalah data primer yaitu dengan pengisian kuesioner. Sampel penelitian ini berjumlah 96 orang. Teknik sampel adalah stratified random sampling. Data dianalisis menggunakan program komputer SPSS menggunakan uji statistik deskriptif dan menampilkan hasil dalam tabel distribusi dan frekuensi. Hasil: Tingkat pengetahuan remaja SMK Negeri 8 Medan tergolong baik $(59,4 \%)$, tingkat sikap tergolong baik $(80,2 \%)$, dan tingkat perilaku tergolong baik (99\%). Kesimpulan: Tingkat pengetahuan, sikap dan perilaku remaja tentang kesehatan reproduksi di SMK Negeri 8 tergolong baik.
\end{abstract}

Kata Kunci: kesehatan reproduksi, pengetahuan, perilaku, remaja, sikap

\section{ABSTRACT}

Background: Reproductive health is one of the most important things for human life, which includes a complete physical, mental, social welfare condition in all matters relating to the function and role of the reproductive system. Reproductive health education should be given since adolescence, because adolescence is a phase towards more mature reproduction. Adolescent problems related to reproductive health, often stem from a lack of information, understanding and awareness to achieve reproductive health. Objectives: This study aims to determine the level of knowledge, attitudes and behavior of adolescents about reproductive health at SMK Negeri 8 Medan. Methods: This study was a descriptive study with a cross sectional design. The research data is primary data, namely by filling out a questionnaire. The sample of this research is 96 people. The sample technique is stratified random sampling. Data were analyzed using the SPSS computer program using descriptive statistical tests and displaying the results in distribution and frequency tables. Results: Knowledge level of adolescents in SMK Negeri 8 Medan is good (59.4\%), attitude level is good (80.2\%) and behavior level is good (99\%). Conclusion: The level of knowledge, attitudes and behavior of adolescents about health reproduction at SMK Negeri 8 is classified as good.

Keywords: adolescent, attitude, behavior, knowledge, reproductive health

Received [6 Jan 2020] | Revised [14 Aug 2020] | Accepted [15 Aug 2020]

\section{PENDAHULUAN}

Menurut WHO, seperlima penduduk dunia terdiri dari remaja berusia 10-19 tahun. Data ini menunjukkan remaja memiliki populasinya yang cukup kompleks di dunia, yaitu yang akan menjadi penerus generasi selanjutnya. ${ }^{[1]}$ Terlebih remaja merupakan masa peralihan fisik, mental, dan sosial. ${ }^{[2]}$ Maka dari itu, 
remaja perlu mendapat perhatian serius, salah satunya adalah pendidikan kesehatan reproduksi. Namun, hasil penelitian SDKI pada tahun 2017 menunjukkan bahwa pengetahuan remaja tentang kesehatan reproduksi belum memadai. Ini ditunjukkan dengan persentase pengetahuan remaja tentang masa subur wanita, yaitu hanya 33 persen remaja putri dan 55 persen remaja putra dari sampel yang benar menjawab. Persentase remaja di Indonesia yang belum mengetahui cara penularan Penyakit Menular Seksual (PMS) adalah 68,8 persen untuk remaja putri dan 66,6 persen untuk remaja putra. Pengetahuan komprehensif HIV-AIDS remaja Indonesia hanya 12 persen untuk remaja putri dan 10,6 persen untuk remaja putra. $^{[3]}$ Ini adalah angka yang sangat memprihatinkan dan akan meningkatkan risiko peningkatan prevalensi HIV-AIDS pada remaja generasi penerus bangsa dan masalah reproduksi lainnya. Menurut pravelensi, kejadian HIV-AIDS di Kota Medan merupakan angka paling tinggi di Sumatera Utara, kelompok usia muda, yaitu 15-24 tahun merupakan kelompok paling banyak. ${ }^{[4]}$ Rendahnya pengetahuan remaja tentang kesehatan seksual dan reproduksi mengakibatkan remaja mulai melakukan perilaku seksual tanpa informasi akurat tentang kesehatan reproduksi, sehingga menempatkan diri mereka pada risiko melakukan praktik perilaku seksual yang tidak aman, dan dapat mengakibatkan penyakit infeksi menular seksual atau kehamilan yang tidak diinginkan. ${ }^{[5]}$

Oleh karena itu, penelitian ini bertujuan untuk mengetahui tingkat pengetahuan, sikap, dan perilaku remaja tentang kesehatan reproduksi dengan sampel Sekolah Menengah Kejuruan (SMK) Negeri 8 Medan. SMK Negeri 8 digunakan sebagai sampel karena menurut Direktorat Pembinaan SMK, Kementerian Pendidikan dan Kebudayaan dalam bahan ajaran kurikulum 2013, SMK tidak mempelajari pelajaran ilmu pengetahuan alam dan ilmu pengetahuan sosial dimana menurut Donald dan Hull, pendidikan kesehatan reproduksi terintregrasi dalam mata pelajaran tersebut. ${ }^{[6]}$ Selain itu, SMK Negeri 8 merupakan sekolah negeri, dimana sampel berasal dari berbagai kalangan dan lebih bervariasi sehingga lebih menggambarkan populasi.

\section{METODE}

Penelitian ini merupakan penelitian survei bersifat deskriptif menggunakan desain penelitian cross sectional. Penelitian ini dilakukan di Sekolah Menengah Kejuruan (SMK) Negeri 8 Medan. Data dalam penelitian ini merupakan data primer yang didapat melalui pengisian kuesioner untuk mengetahui tingkat pengetahuan, sikap dan perilaku remaja tentang kesehatan reproduksi di SMK Negeri 8 Medan. Sampel dalam penelitian ini ialah siswa SMK Negeri 8 Medan yang berada dalam rentang usia 10-19 tahun. Berdasarkan perhitungan rumus slovin, diperoleh 96 orang sampel dalam penelitian ini. Kriteria inklusi penelitian ini merupakan siswa aktif yang menjalani proses pembelajaran di SMK Negeri 8 Medan, yakni siswa kelas X, XI dan XII. Sedangkan, kriteria eksklusi pada penelitian ini adalah siswa yang tidak hadir dan tidak mengisi kuesioner penelitian. Sampel didapat dengan metode stratified random sampling, sehingga semua siswa dengan tingkatan kelasnya mendapat kesempatan yang sama untuk menjadi sampel penelitian. Kuesioner penelitian ini menggunakan modifikasi kuesioner penelitian sebelumnya yang berjudul "Perbandingan Pengetahuan Dan Sikap Remaja Tentang Kesehatan Reproduksi di MAN Meulaboh-1 dan SMAN 2 Meulaboh Kabupaten Aceh Barat Tahun 2013" dan kuesioner SDKI17-R tentang kesehatan reproduksi remaja yang kemudian dilakukan uji validitas dan reabilitas kembali. Kuesioner tersebut terdiri dari pengetahuan (8), sikap (10), dan perilaku (11). Kuesioner ini digunakan untuk menilai tingkat pengetahuan remaja tentang kesehatan reproduksi dengan benar (1) dan 
salah (0). Kuesioner sikap dan perilaku memiliki 2 jenis pertanyaan yaitu pertanyaan positif, yaitu sangat setuju (4), setuju (3), tidak setuju (2), dan sangat tidak setuju (1). Nilai kuesioner terdiri dari kategori baik (>75\%), sedang (74-50\%) dan kurang $(<50 \%)$. Begitu sebaliknya untuk pertanyaan negatif. Selain itu, diperoleh juga data sekunder didapatkan dari SMK Negeri 8 Medan serta studi kepustakaan dan studi literatur yang terkait. Setelah hasil didapatkan, data akan dianalisis dengan program komputer SPSS menggunakan uji statistik deskriptif dan ditampilkan dalam bentuk tabel distribusi dan frekuensi.

\section{HASIL}

Pada penelitian ini menunjukkan bahwa distribusi usia responden paling banyak adalah pada usia 16 tahun, dengan jumlah 32 orang $(33,3 \%)$. Jenis kelamin perempuan merupakan responden paling banyak dengan jumlah 74 orang $(77,1 \%)$.

Distribusi jurusan responden paling banyak adalah jurusan tata boga yaitu berjumlah 26 orang $(27,1 \%)$ dengan sosial ekonomi sedang merupakan sosial ekonomi paling banyak berjumlah 32 orang $(33,3 \%)$.

Hasil penelitian ini mengenai tingkat pengetahuan responden yang terbanyak adalah tingkat pengetahuan kategori baik dengan jumlah 57 orang $(59,4 \%)$, sikap dengan kategori baik dengan jumlah 77 orang $(80,2 \%)$ dan perilaku dengan kategori baik 95 orang (99\%). (Tabel 1)

Tabel 1. Distribusi tingkat pengetahuan, sikap dan perilaku remaja tentang kesehatan reproduksi

\begin{tabular}{lccc}
\hline & $\begin{array}{c}\text { Baik } \\
(\boldsymbol{\%})\end{array}$ & $\begin{array}{c}\text { Cukup } \\
(\boldsymbol{\%})\end{array}$ & $\begin{array}{c}\text { Rendah } \\
(\boldsymbol{\%})\end{array}$ \\
\hline \multirow{2}{*}{ Pengetahuan } & 57 & 30 & 9 \\
& $(59,4)$ & $(31,3)$ & $(9,4)$ \\
\multirow{2}{*}{ Sikap } & 77 & 19 & 0 \\
\multirow{3}{*}{ Perilaku } & $(80,2)$ & $(19,8)$ & $(0)$ \\
& 95 & 1 & 0 \\
& $(99)$ & $(1)$ & $(0)$ \\
\hline
\end{tabular}

Hampir semua responden pada penelitian ini sudah pernah mendapatkan informasi tentang kesehatan reproduksi
(Tabel 2), paling dominan dari guru yaitu 75 respon $(35,5 \%)$ dan diikuti dari internet yaitu 40 respon (19\%). Informasi dari orang tua dan tenaga kesehatan berada di urutan selanjutnya yaitu 26 respon $(12,3 \%)$.

Tabel 2. Distribusi frekuensi berdasarkan sumber informasi kesehatan reproduksi

\begin{tabular}{lcc}
\hline Sumber Informasi & N & \% \\
\hline Guru & 75 & 35,5 \\
Internet & 40 & 19 \\
Orang Tua & 26 & 12,3 \\
Tenaga Kesehatan & 26 & 12,3 \\
Teman Sebaya & 20 & 9,5 \\
Tokoh Agama & 12 & 5,7 \\
Buku/Majalah/Surat & 11 & 5,2 \\
Kabar/Radio/Televisi & 1 & 0,5 \\
Tidak ada & 211 & 100 \\
\hline Total Respon & &
\end{tabular}

Responden dengan umur 19 tahun yaitu 1 orang $(100 \%)$ dan 18 tahun yaitu 5 orang $(100 \%)$ memiliki pengetahuan paling baik. Selanjutnya, responden dengan jenis kelamin perempuan memiliki tingkat pengetahuan yang paling baik yaitu 39 orang $(68,4 \%)$. Jurusan tata boga memiliki pengetahuan yang paling baik yaitu 17 orang $(29.8 \%)$. Responden dengan sosial ekonomi tinggi memiliki tingkat pengetahuan yang paling baik yaitu 19 orang $(33,3 \%)$. (Tabel 3)

\section{PEMBAHASAN}

Pada penelitian ini menunjukkan bahwa tingkat pengetahuan responden tegolong baik dengan jumlah 57 orang $(59,4 \%)$, sesuai dengan hasil penelitian Sirupa dalam pengetahuan, sikap, dan perilaku remaja tentang kesehatan reproduksi pengetahuan remaja yang dilakukan di SMK Negeri 1 Manado dan SMK Kristen Getsemani Manado, yaitu tingkat pengetahuan di kedua sekolah tersebut tentang kesehatan reproduksi tergolong baik, yaitu sebanyak 182 responden $(91 \%){ }^{[7]}$ Hasil Survei Demografi dan Kesehatan Indonesia 2017 (SDKI 2017) tentang Kesehatan Reproduksi Remaja yang dilaksanakan oleh 
Badan Pusat Statistik (BPS) bekerja sama dengan Badan Kependudukan dan Keluarga Berencana Nasional (BKKBN) dan Kementerian Kesehatan menunjukkan bahwa pengetahuan remaja tentang kesehatan reproduksi belum memadai. ${ }^{[3]}$

Tabel 3. Distribusi tingkat pengetahuan berdasarkan umur, jenis kelamin, jurusan dan sosial ekonomi

\begin{tabular}{|c|c|c|c|c|}
\hline & $\begin{array}{l}\text { Total }(\%) \\
\text { n=96 }(100 \%)\end{array}$ & Baik (\%) & Cukup (\%) & Rendah (\%) \\
\hline \multicolumn{5}{|l|}{ Umur } \\
\hline 14 & $3(3.1)$ & $2(66.7)$ & $1(33.3)$ & $0(0)$ \\
\hline 15 & $31(32.3)$ & $15(48.4)$ & $12(38.7)$ & $4(12.9)$ \\
\hline 16 & $32(33.3)$ & $18(56.3)$ & $10(31.3)$ & $4(12.5)$ \\
\hline 17 & $24(25.0)$ & $16(66.7)$ & 7 (29.2) & $1(4.2)$ \\
\hline 18 & $5(5.2)$ & $5(100)$ & $0(0)$ & $0(0)$ \\
\hline 19 & $1(1.0)$ & $1(100)$ & $0(0)$ & $0(0)$ \\
\hline \multicolumn{5}{|l|}{ Jenis Kelamin } \\
\hline Laki-laki & $22(22.9)$ & $18(31.6)$ & $4(13.3)$ & $0(0)$ \\
\hline Perempuan & $74(77.1)$ & $39(68.4)$ & $26(87.6)$ & $9(100)$ \\
\hline \multicolumn{5}{|l|}{ Jurusan } \\
\hline Perhotelan & $22(22.9)$ & $14(24.6)$ & $6(20)$ & $2(22.2)$ \\
\hline Tata Boga & $26(27.1)$ & $17(29.8)$ & $8(26.7)$ & $1(11.1)$ \\
\hline Tata Rias & $23(24)$ & $11(19.3)$ & $10(33.3)$ & $2(22.2)$ \\
\hline Tata Busana & $25(26)$ & $15(26.3)$ & $6(20)$ & $4(44.4)$ \\
\hline \multicolumn{5}{|l|}{ Sosial Ekonomi } \\
\hline Sangat Tinggi & $23(24)$ & $16(28.1)$ & $5(16.7)$ & $2(22.2)$ \\
\hline Tinggi & $26(27.1)$ & $19(33.3)$ & $7(23.3)$ & $0(0)$ \\
\hline Sedang & $32(32.3)$ & $14(24.6)$ & $15(50)$ & $3(33.3)$ \\
\hline Rendah & $15(17.6)$ & $8(14)$ & $3(10)$ & $4(44.4)$ \\
\hline
\end{tabular}

Sikap responden tentang kesehatan reproduksi tergolong baik sebanyak 77 orang $(80,2 \%)$. Hasil ini sebanding dengan hasil penelitian Sirupa bahwa sikap remaja tentang kesehatan reproduksi tergolong baik sebanyak 192 responden (96\%). Nilai perilaku responden terhadap kesehatan reproduksi tegolong baik yaitu 95 orang $(99 \%) .{ }^{[7]}$ Tingkat pengetahuan tentang kesehatan reproduksi yang baik dari responden mempengaruhi cara responden bersikap. Hal ini sesuai dengan pernyataan Sarwono yang menyatakan sikap seseorang dapat berubah dengan diperolehnya informasi tentang objek tertentu, melalui persuasif serta tekanan dari kelompok sosialnya. Menurut Green, perilaku dipengaruhi oleh pengetahuan dan sikap. Semakin baik pengetahuannya, semakin baik pula sikap dan perilakunya. Perilaku remaja terkait masalah kesehatan reproduksi menunjukkan adanya pergeseran nilai-nilai dan norma. ${ }^{[8]}$

Hampir semua responden pada penelitian ini sudah pernah mendapatkan informasi tentang kesehatan reproduksi, paling dominan dari guru yaitu 75 responden $(35,5 \%)$. Sumber informasi yang paling sedikit diperoleh dari media massa (buku /majalah /suratkabar /radio /televisi) yaitu 11 responden $(5,2 \%)$. Remaja yang tidak mendapatkan informasi tentang kesehatan reproduksi sebanyak 1 responden $(0,5 \%)$. Hasil penelitian ini sesuai dengan SKDI 2017 yaitu sumber informasi remaja tentang kesehatan reproduksi yang paling tinggi pada umur 15-19 tahun adalah guru dengan persentase $81,4 \% .{ }^{[3]}$

Responden dalam penelitian ini dibedakan menurut umur, jenis kelamin, jurusan dan sosial ekonomi. Jumlah responden paling banyak adalah pada usia 
16 tahun berjumlah 32 orang $(33,3 \%)$ dengan tingkat pengetahuan responden tegolong baik dengan jumlah 57 orang $(59,4 \%)$, sesuai dengan hasil penelitian Sirupa dalam pengetahuan, sikap, dan perilaku remaja tentang kesehatan reproduksi pengetahuan remaja yang dilakukan di SMK Negeri 1 Manado dan SMK Kristen Getsemani Manado, yaitu tingkat pengetahuan di kedua sekolah tersebut tentang kesehatan reproduksi tergolong baik, yaitu sebanyak 182 responden $(91 \%) .{ }^{[7]}$

Pada penelitian ini responden dengan jenis kelamin perempuan merupakan responden paling banyak dengan jumlah 74 orang $(77,1 \%)$ dengan tingkat pengetahuan yang lebih tinggi yaitu 39 orang $(68,4 \%)$ dibandingkan dengan tingkat pengetahuan pada responden dengan jenis kelamin lakilaki yaitu 18 orang $(31,6 \%)$. Hasil penelitian ini sebanding dengan penelitian Simbar dalam Reproductive health knowledge, attitudes and practices of Iranian college students, yaitu tingkat pengetahuan remaja puteri lebih tinggi (56\%) dibandingkan remaja putera $(55 \%){ }^{[9]}$

Distribusi jurusan responden paling banyak adalah jurusan tata boga yaitu berjumlah 26 orang $(27,1 \%)$ dengan tingkat pengetahuan jurusan pengetahuan baik yang paling banyak pula yaitu 17 orang (29.8\%). Salah satu faktor yang dapat mempengaruhi suatu pengetahuan menurut Notoatmodjo adalah pendidikan. Pendidikan merupakan sebuah proses untuk mengembangkan kemampuan seseorang melalui pengetahuan. Suatu pendidikan akan menentukan tingkat pengetahuan seseorang. Semakin tinggi tingkat pengetahuannya semakin tinggi pula tingkat pengetahuannya. Menurut Simbar dalam penelitiannya, jurusan pendidikan memengaruhi dari tingkat pengetahuan remaja tentang kesehatan. Hal ini disebabkan oleh pendidikan kesehatan reproduksi yang sudah didapatkan sebelumnya, pola asuh keluarga, dan sosial ekonomi. ${ }^{[9]}$
Responden dalam penelitian ini memiliki sosial ekonomi dalam kategori sedang yang paling banyak yang berjumlah 32 orang $(33,3 \%)$. Namun untuk tingkat pengetahuannya, responden dengan sosial ekonomi tinggi memiliki tingkat pengetahuan baik paling tinggi yaitu 19 orang $(33,3 \%)$. Hasil penelitian ini sesuai dengan SKDI 2017 yaitu responden dengan sosial ekonomi tinggi dan menegah keatas pada rentang usia 15-19 tahun memiliki tingkat pengetahuan paling baik yaitu $22 \%$ dan responden yang memiliki tingkat pengetahuan terendah yaitu responden dengan sosial ekonomi terendah yaitu $14,6 \%{ }^{[3]}$ Keadaan sosial ekonomi yang baik akan menyebabkan terpenuhinya seluruh kebutuhan baik kebutuhan primer, kebutuhan sekunder ataupun kebutuhan tersier. Dengan terpenuhinya kebutuhan itu, maka akses untuk mendapatkan pengetahuan yang lebih baik juga lebih mudah misalnya melalui pendidikan dan media massa. ${ }^{[10]}$

\section{KESIMPULAN}

Tingkat pengetahuan remaja di SMK Negeri 8 Medan tergolong baik diikuti dengan sikap dan perilaku yang baik pula. Dari penelitian ini didapatkan hasil bahwa hampir semua responden sudah pernah mendapatkan informasi tentang kesehatan reproduksi, paling dominan dari guru dan internet. Sumber informasi yang paling sedikit diperoleh dari media massa. Responden dengan umur 19 dan 18 tahun merupakan umur yang memiliki pengetahuan paling baik. Jika dibandingkan berdasarkan jenis kelamin, responden dengan jenis kelamin perempuan memiliki pengetahuan tentang kesehatan reproduksi yang lebih baik dibandingkan laki-laki. Selanjutnya, responden dengan jurusan tata boga memiliki pengetahuan paling baik dan responden dengan sosial ekonomi tinggi memiliki pengetahuan paling baik dibandingkan tingkat sosial ekonomi yang lainnya. 


\section{SARAN}

Dari hasil yang ditemukan di SMK Negeri 8 Medan, sebaiknya pihak Dinas Kesehatan Kota Medan lebih meningkatkan penyuluhan atau promosi kesehatan reproduksi dengan sasaran pelajar sekolah selaku instansi pendidik dan masyarakat, terhadap upaya kesehatan reproduksi terutama mengenai kebersihan alat reproduksi, penyakit menular seksual dan HIV-AIDS, serta dampak kehamilan yang tidak diinginkan, sehingga dapat mempertahankan dan meningkatkan lagi pengetahuan dan kesadaran terhadap kesehatan reproduksi. Diharapkan dapat terjadi penurunan angka kejadian masalah kesehatan reproduksi. Bagi peneliti selanjutnya, diharapkan untuk membuat penelitian yang lebih luas jangkauannya, sehingga dapat menggambarkan hasil yang lebih baik lagi.

\section{DAFTAR PUSTAKA}

[1] Kementerian Kesehatan RI. Situasi Kesehatan Remaja di Indonesia. Jakarta: Pusat Data dan Informasi Kementrian Kesehatan RI; 2017.

[2] Purbono IA, Prabawati M, Tarma. Tingkat pengetahuan remaja tentang kesehatan reproduksi. J FamilyEdu. 2015;1(2).

[3] Tim SDKI 2017. Survei Demografi dan Kesehatan Indonesia 2017: Kesehatan Reproduksi Remaja. Jakarta: Badan Kependudukan dan Keluarga Berencana Nasional; 2017.

[4] Badan Pusat Statistik Kota Medan. Kota Medan dalam Angka: Medan Municipality in Figure 2019. Medan: Badan Pusat Statistik Kota Medan; 2019. 137 p.

[5] Wong LP. An exploration of knowledge, attitudes and behaviours of young multiethnic Muslimmajority society in Malaysia in relation to reproductive and premarital sexual practices. BMC Public Health [Internet]. 2012 Dec [cited 2019 May 26];12(1). Available from:

https://bmcpublichealth.biomedcentr al.com/articles/10.1186/1471-2458$\underline{12-865}$

[6] Utomo I, McDonald P, Hull. Improving reproductive health education in the Indonesian national curriculum. Gend Reprod Health Study Policy Brief. 2013;2.

[7] Sirupa T, Wantania J, Suparman E. Pengetahuan, sikap dan perilaku remaja tentang kesehatan reproduksi. J E-Clin ECI. 2016;4(2). doi: 10.35790/ecl.4.2.2016.14370

[8] Sarwono SW. Psikologi remaja. Jakarta: Rajawali; 2006.

[9] Simbar M, Tehrani FR, Hashemi Z. Reproductive health knowledge, attitudes and practices of Iranian college students. East Mediterr Health J. 2005;11(5):10.

[10] Notoatmodjo S. Ilmu kesehatan masyarakat: prinsip prinsip dasar. Jakarta: PT Rineka Cipta; 2003. 